\title{
Comparison of Different Methods of Measuring Illuminance in the Indoor of Office and Educational Buildings
}

\author{
Majid Hajibabaei ${ }^{1, *}$; Samira Kord ${ }^{1,2}$; Ezat Rasooli ${ }^{1,2}$ \\ ${ }^{1}$ Department of Occupational Hygiene, School of Health, Ahvaz Jundishapur University of Medical Sciences, Ahvaz, IR Iran \\ $2^{2}$ Student Research Committee, Ahvaz Jundishapur University of Medical Sciences, Ahvaz, IR Iran \\ ${ }^{*}$ Corresponding author: Majid Hajibabaei, Department of Occupational Hygiene, School of Health, Ahvaz Jundishapur University of Medical Sciences, Ahvaz, IR Iran. Tel: +98- \\ 6113738269, Fax: +98-6113738282, E-mail: mhajibabaei2050@gmail.com.
}

Received: February 1, 2014; Revised: May 3, 2014; Accepted: May 4, 2014

Background: The light is one of the electromagnetic waves that can be created from conversion of electrical energy into a visible energy for human eye. The illumination intensity is measured in order to compare with the quality standards of light and for estimation of energy waste and lighting system performance. Therefore, the systematic and scientific measurement principles in data validation are very important.

Objectives: The purpose of this study was to measure the actual artificial lighting by various valid procedures.

Materials and Methods: The overall, artificial and natural lighting has been measured at different times and in rooms with open and closed blinds mode and based on the various measuring stations.

Results: The results show the artificial lighting obtained by difference methods of the overall lighting from natural lighting in closed blinds mode equal to 266 Lux and night lighting 283.5 Lux that they have no significant differences with each other $(\mathrm{P}=0.269)$. As well as the illumination intensity obtained from a standard grid method is 283.5 Lux and illumination intensity based on Luminaires layout model is 274 Lux with no significant difference $(\mathrm{P}=0.269)$

Conclusions: The present study shows that method of difference (subtracting the overall light from natural light) can be a good option to measure the illumination intensity of artificial lighting system in any state (open or closed curtains) and time of the day and a standard method for measuring the lighting per residential, administrative and training units.

Keywords: Illumination; Time; Methods

\section{Background}

Light is one of the electromagnetic waves that can be created from conversion of electrical energy into visible energy, visible by the human eye. Due to the sensitivity of the eye, providing suitable illumination intensity during certain frequencies is essential in order to optimize the performance (1). Since 1990, the lightening of good quality was defined as a lightening that provides a balance between the needs of humans, economic and environmental issues and architecture design $(2,3)$. Hence, the lighting should provide a good performance (4). However, according to the electric energy consumption, the topics of economic and energy savings are also very important and therefore, estimates of the amount of energy waste and the amount of performance in lighting systems, especially the artificial lighting is the requirements of each country (5-7). Therefore, measurement of illumination intensity in order to assess the amount of exposure of individuals for estimation of health risks and the calculation of artificial lighting system performance is important and necessary. Therefore, there is a need for a detailed evaluation of illumination intensity (8-10). There are several patterns and ways to measure the artificial illumination intensity. In addition to this issue, time is one of the most important discussions on the measurement of illumination intensity. Measurement of the artificial illumination intensity is proposed at night time or day when room curtains have been drawn or the parasol has been used or in the final hours of the day (11). Furthermore, another way is also expressed in this regard so that it measures illumination intensity in two states (the artificial lighting system ON , and artificial lighting system OFF ) at any time of day; the difference between these values shows the amount of artificial illumination intensity $(12,13)$. Measuring stations are also other important issues in measurement of the artificial illumination intensity. In this case, if the lighting is uniform and the cavities of the rooms are normal, the stations can be selected based on the layout of the luminaires (IESNA method) and if the lighting is not uniform and also the cavity is not normal, it is measured in a form of grid in 2 $\times 2$ feet and the arithmetic mean of all the points is taken (11). Another way also is that the number of stations can be calculated on the basis of the room index and is calculated by dividing the total area of the room by minimum points; and in their center, illumination intensity is measured

Copyright @ 2014, Ahvaz Jundishapur University of Medical Sciences; Published by Kowsar Corp. This is an open-access article distributed under the terms of the Creative Commons Attribution License, which permits unrestricted use, distribution, and reproduction in any medium, provided the original work is properly cited. 
and the arithmetic mean of all the points is taken (11,13-16). The purpose of this cross-sectional study was performed in order to measure the illumination intensity in the offices and educational buildings in a university by various methods and patterns that are expressed in the studies and standards. Because of impossibility of measuring the illumination intensity at night in office and educational buildings, this study suggests a method to solve this problem in order to measuring illuminance during working.

\section{Objectives}

This study is to measure the actual artificial lighting by various procedures to provide a valid method for the following practical purposes: accurate representative value for illuminance to maintain the quality standards of lighting and to estimate the energy consumption.

\section{Materials and Methods}

In the present study, 50 spaces (educational and office) were selected based on the objectives of the study and according to the orientation of the room (North or South), windows, blinds and its parasols as well as measuring time. The illumination intensity was measured in the same rooms by two methods, grid method that is expressed in the following and the measuring method based on the layout of luminaires (illuminating Engineering Society of North America) that was selected regular areas with symmetrically spaced luminaires in two or more rows then according to Figure 1 determine the average illuminance in the areas by using the equation 1 (11). Equation 1:

$$
E_{\text {ave }}=\frac{R(N-1)(M-1)+Q(N-1)+T(M-1)+P}{\mathrm{NM}}
$$

N, Number of Luminaires Per Row; $M$, Number of Rows; $\mathrm{R}, \mathrm{Q}, \mathrm{T}, \mathrm{P}$, Average Illuminance in the Areas.

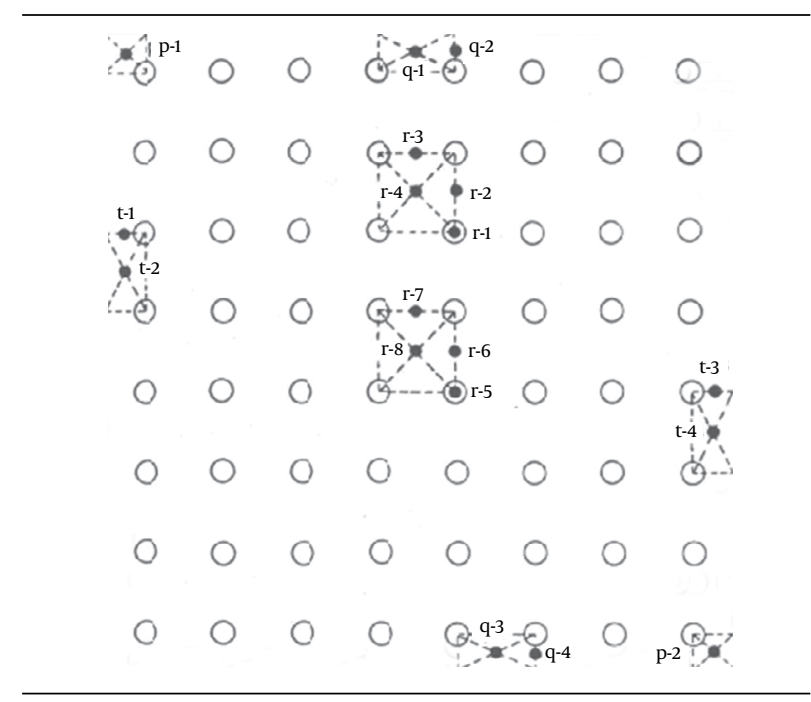

Figure 1. Regular Area With Symmetrically Located Single Luminaire
Also, In order to determine the artificial illumination intensity by grid method, at first, room index (RI) was calculated based on the Equation 2 then, minimum points of the measure in each range were determined based on this index (Equation 2) (14).

Equation 2:

$$
\mathrm{RI}=(L W) /\left[h_{m}(L+W)\right]
$$

$\mathrm{W}$ and $\mathrm{L}$ are the length and width of the room measured; the $h_{m}$ is also the height of the luminaires from the work surface.

After the calculation of the room index, if the index is less than one, the minimum number of points measured in the room should not be less than nine points. If the index is calculated between one and two, the minimum number of points should not be less than 18 points. If the index was between two and three, minimum point numbers should not be less than 25; if between three and four, minimum point numbers should not be less than 36 ; and if four and above, minimum point numbers should not be less than 50 . On the basis of the minimum number of points measured, the room is divided into equal squares and the intencity was measured by a Luxmeter (TES-1336A Model, made in Taiwan) at a height of $100 \mathrm{~cm}$ from the floor in the center of each square. Illumination intensity in different time situations (in each method) has been measured as below $(12,14,17)$. In the beginning, at noon (11-14), in the state that room blinds have been open and the artificial lighting system was turned on, illumination intensity was measured (overall lighting) and in this case, artificial lighting system was also turned off and the illumination intensity was measured (the daylight) and artificial illumination intensity has been calculated by the difference between these two amount (this method in this article is called the difference method). Then the blinds have been drawn (the closed blinds) and the same measurements have been done in terms of artificial lighting system being switched ON and OFF, and artificial lighting has been measured. Then in the evening hours (15.00-16.40) when the blinds have been in the two states of opened and closed and illumination intensity has been measured only in a state that the artificial lighting system has been ON in order to provide the same natural light. Also the illumination intensity was measured at night in the same rooms by two network methods that was expressed in the above and the measuring method based on the layout of luminaires (illuminating Engineering Society of North America) and in order to remove the external lights, blinds were drawn up as well. In this study, as mentioned in the above, based on the objectives of the study, educational and office areas randomly were selected in a university and the research data were transferred into SPSS version 15 to perform statistical analysis; using t-test and analysis of variance and linear regression with 0.05 significance level. ANOVA test was used for comparison of 
different measurements; t-test was used for comparison of the variable mentioned between the patterns of measurement station (grid and based on the layout of luminaires). Furthermore, a linear regression was used to verify the connection between the increase in daylight and artificial illuminance calculated by difference method.

\section{Results}

Artificial illumination intensity measurement results at different times have been shown in the Tables 1 and 2. The results of illumination intensity in the noon time mea- sured in different situations have been shown in Table 3. Although most of the light received are from the South windows, the results of the illumination intensity of the rooms that only have South windows shows artificial illuminance calculated by the difference method in the two opening and closing curtains has been respectively equal to 294.3 Lux and 250 Lux and no significant difference existed between them $(P=0.859)$. But the overall illumination intensity (daylight and artificial) that has been received in South windows in the mode of opening and closing blinds has been equal to 723 and 377 Lux, respectively that show a significant difference $(P=0.013)$.

\begin{tabular}{lcc}
\hline Table 1. Comparison Between Mean Value Artificial Illumination Intensity and the Grid Stationing in a Closed Blinds ${ }^{\text {a,b }}$ & \multicolumn{1}{c}{ Illumination Intensity } \\
\hline Measurement Time & $266 \pm 158.63$ & $312-221$ \\
\hline Noon (artificial lighting to difference method) & $283.5 \pm 149$ \\
Night & $317 \pm 164$ & $345-241$ \\
Evening & $363-270$ \\
\hline
\end{tabular}

a Data are presented as mean \pm SD.

$\mathrm{b}_{\mathrm{P}=0.269 \text {. }}$

Table 2. Comparison Between Mean Value Artificial Illumination and the Grid Stationing in an Open Blinds ${ }^{a}$

\begin{tabular}{|c|c|c|c|c|}
\hline Measurement Time & Illumination Intensity & Confidence Interval 95\% & & \\
\hline $\begin{array}{l}\text { Noon (artificial lighting to } \\
\text { difference method) }\end{array}$ & $289 \pm 22$ & $233-245$ & \multirow[t]{2}{*}{0.9} & \multirow{3}{*}{0.000} \\
\hline Night (artificial lighting) & $283.5 \pm 21$ & $325-241$ & & \\
\hline Evening (overall lighting) & $460 \pm 35$ & $419-330$ & - & \\
\hline
\end{tabular}

a Data are presented as mean \pm SE.

Table 3. Comparison Between Mean Value Overall Illumination Intensity and the Grid Stationing in a Closed Blinds ${ }^{\mathrm{a}}$

\begin{tabular}{lccc}
\hline Measurement Time & Illumination Intensity & Confidence Interval 95\% & P Value \\
\hline Noon (overall lighting) & $364 \pm 25.5$ & $415-312.7$ & 0.016 \\
Night (artificial lighting) & $283.5 \pm 21$ & $325-241$ & 0.054 \\
Evening (overall lighting) & $317 \pm 23$ & $363-270$ & - \\
\hline
\end{tabular}

a Data are presented as mean \pm SE.

Table 4. Illumination Intensity at the Noon Time in Different Circumstances

\begin{tabular}{|c|c|c|}
\hline Types of Lighting & Illumination Intensity & P Value \\
\hline Overall & & 0.000 \\
\hline Open & $625.5 \pm 45.5$ & \\
\hline Closed & $364 \pm 25.4$ & \\
\hline Artificial by difference method & & 0.91 \\
\hline Open & $289 \pm 21.9$ & \\
\hline Closed & $266.7 \pm 22.4$ & \\
\hline Natural & & 0.000 \\
\hline Open & $336.8 \pm 38$ & \\
\hline Closed & $102.5 \pm 15.8$ & \\
\hline
\end{tabular}


Hajibabaei M et al.

Table 5. Comparison Between Mean value Artificial Illumination Intensity at Night Based on the Stationing a,b

\begin{tabular}{lcc}
\hline Measuring method & Illumination Intensity & Confidence Interval \\
\hline Grid & $283.5 \pm 21$ & $749-91$ \\
Based on the layout of luminaires & $280 \pm 21.8$ & $717-4$ \\
\hline a Data are presented as mean \pm SE. & & \\
$\mathrm{b}_{\mathrm{P}=0.71 .}$ & & \\
\end{tabular}

\begin{tabular}{|c|c|c|}
\hline Measuring method & The Average Illumination Intensity & Confidence Interval \\
\hline Grid & $279 \pm 43.7$ & $102-1153$ \\
\hline Based on the layout of luminaires & $249 \pm 29$ & $52-634$ \\
\hline
\end{tabular}

$\mathrm{b}_{\mathrm{P}=0.573 \text {. }}$ Data are presented as mean $\pm \mathrm{SE}$

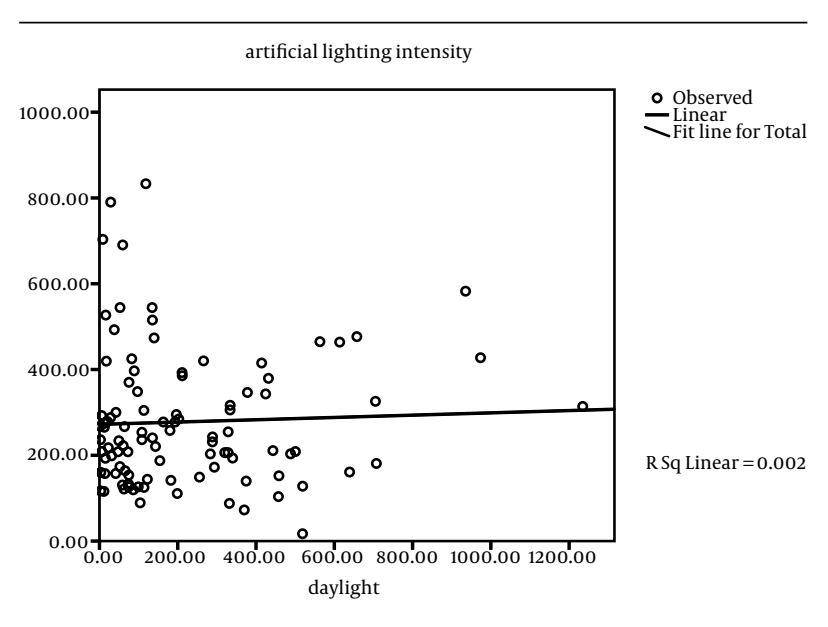

Figure 2. The Relationship Between the Daylight and Artificial Illuminance (by Different Method)

\section{Discussion}

The most important key point that was evaluated in this study was to compare different times artificial illumination intensity (noon - evening - night) in different ways, in order to estimate the acceptable and actual artificial lighting systems. Based on the results achieved (Table 1), when the blinds are drawn (closed), daylight has reached its lowest amount and no significant difference was seen between the illumination intensity at different times ( $\mathrm{P}=$ 0.269). In addition, if the blinds were open, no significant difference was seen between the artificial illumination intensity by the difference method and night illumination intensity $(P=0.9)$. However, significant difference was seen between evening and night illumination intensity $(\mathrm{P}=0.000)$ (Table 4$)$. Regarding the creation of blinds and sunshades in the evening time, the overall lighting (natural and artificial) measurements can be regarded as artificial lighting, however, it has a difference of 33.5 Lux with the actual lighting of the night but this difference was not statistically significant (Table 5) (11). But according to Table 3, measurements of overall illumination intensity in the noon time by dragging the blinds, is not considered as real artificial lighting and it has no significant relationship with artificial illumination (night). The results show even when the blind is opened, artificial illumination intensity of noon time (difference method) and night time have not significant differences, and have a very tiny compared to the differences (14). As can be observed in Table 4, in a case wherein the difference method the blinds are open or closed, there is no significant difference between the values obtained from the artificial illumination intensity $(P=0.9)$. Hence the difference method can be a better method to evaluate the intensity of lighting in office environments and training relative to measuring the illumination intensity compared to the measurement of the illumination intensity in the evening with open or closed blinds. One of the issues that may actually be questioned in this regard is whether due to the increased daylight, artificial illumination intensity obtained from the difference between the overall lighting and daylight may be increased (difference method) or significantly changes? According to Figure 2, increasing daylight has had no significant impact in artificial lighting by the difference method $(\mathrm{P}=0.57)$. Also, this study has focused on the topic of measuring methods based on the stationing as well. As can be seen in Table 5, no significant differences was seen between illumination intensity based on the layout of the luminaires and the grid method $(P=0.71)$. As seen in Table 6 , when the overall lighting is taken, the results of the illumination intensity with these two methods in the closed blinds mode, is not significant and can be used as a method for measuring the illumination intensity. However, this is if the layout of the luminaires is uniform and lighting is properly distributed in the room. This study merely focused on the effects of unusual room cavity ratios or highly non-uniform illumination. In order to measure energy waste and efficiency of lighting systems as well as determine the quality standards of lighting, the detailed and actual illumination intensity of artificial system is very important. The study indicated that the artificial illumination intensity can be calculated at any time of the day by measuring the overall 


\section{Hajibabaei M et al.}

illumination intensity and daylight and their difference (difference method) and this value can be considered as equal to the real lighting of artificial systems in any space. It can be obtained by both a standard grid method and by pattern methods of layout of the luminaires.

\section{Acknowledgements}

The authors appreciate and thank the Research Deputy vice-chancellor for research affairs of Ahvaz Jundishapur University of Medical Sciences, particularly the Research Consultation Center (RCC) for technical support.

\section{Authors Contributions}

Majid Hajibabaei: Research concept and design, Data analysis and interpretation, Writing the article, Critical revision of the article, Final approval of article; Samira Kord and Ezat Rasooli: Collection and assembly of data.

\section{Funding/Support}

This article was supported by Ahvaz Jundishapur University of Medical Sciences.

\section{References}

1. Parsons KC. Environmental ergonomics: a review of principles, methods and models. Appl Ergon. 2000;31(6):581-94.

2. Bellia L, Bisegna F, Spada G. Lighting in indoor environments: Visual and non-visual effects of light sources with different spectral power distributions. Build Environ. 2011;46(10):1984-92.

3. Reinhold K, Tint P. Lighting of workplaces and health risks. Electron Electr Eng. 2009;90(2):11-4.

4. Juslén $\mathrm{H}$, Tenner A. Mechanisms involved in enhancing human performance by changing the lighting in the industrial work- place. Int J Ind Ergon. 2005;35(9):843-55.

5. Linhart F, Scartezzini JL. Evening office lighting-visual comfort vs. energy efficiency vs. performance? Build Environ. 2011;46(5):981-9.

6. Habel J, Zak P. Energy performance of lighting systems. Prz Elektrotech. 2011;87:20-4.

7. Linhart F. Energetic, Visual and Non-Visual Aspects of Office Lighting. 2010; Available from: http://infoscience.epfl.ch/record/143430.

8. Roisin B, Bodart M, Deneyer A, D'herdt P. Lighting energy savings in offices using different control systems and their real consumption. Energy Build. 2008;40(4):514-23.

9. Dubois MC, Blomsterberg A. Energy saving potential and strategies for electric lighting in future North European, low energy office buildings: A literature review. Energy Build. 2011;43(10):257282.

10. Fjeld T. The effect of interior planting on health and discomfort among workers and school children. Horttechnology. 2000;10(1):46-52.

11. Illuminating Engineering Society of North America.. IESNA Lighting Handbook. 9th ed. New York, NY: Illuminating Engineering Society of North America; 2000.

12. Kandar MZ, Sulaiman MS, Rashid YR, Ossen DR, Abdullah AM, Wah LY, et al. Investigating Daylight Quality In Malaysian Government Office Buildings Through Daylight Factor and Surface Luminance. Eng Technol. 2011;59.

13. Winterbottom M, Wilkins A. Lighting and discomfort in the classroom. J Environ Psychol. 2009;29(1):63-75.

14. Chartered Institution of Building Services Engineers. Office Lighting Guide LG7 Society of Light and Lighting. In: CIBSE, editor. London; 2005.

15. Majid F, Azimi PS, Arghami S. Measurement of the illumination in irregular geometric libraries of Zanjan City with geospatial information system (GIS). J Zanjan Univ Med Sci Health Serv. 2009;17(66):61-70.

16. Ghotbi Ravandi MR, Khanjani N, Nadri F, Nadri A, Ahmadian M Toolabi A. Evaluation of illumination intensity and ultraviolet radiation at Kerman Medical University libraries. Iran Occup Health. 2012;8(4):29-35.

17. Li D, H. W, Cheung KL, Wong SL, Lam TNT. An analysis of energy-efficient light fittings and lighting controls. Appl Energy. 2010;87(2):558-67. 